\title{
The Scapholunate Ligament Complex
}

\author{
José Laranjeira Branco, MD ${ }^{1}$ \\ ${ }^{1}$ British Hospital, Lisbon XXI, Portugal \\ J Wrist Surg 2013;282.
}

Although the full pathogenesis of the Scapholunate LigamentComplex (SLLC) is not yet completely understood and remains a challenging subject, one must consider that a great deal of progress has been made in the recent past, on the comprehension of the different stages of its lesion, and by consequence, on the treatment options available.

It also an unavoidable truth, that wrist arthroscopy brought about a clear and sound knowledge of the precise dimension and pattern of the intercarpal lesions, contributing to improved and more accurate classification systems that permit a better definition between attenuation versus instability and the appropriate proposed treatment for its resolution.

The excellent articles included in this issue of the Journal of Wrist Surgery, show us that the move is on its way, and the all inside arthroscopic procedures for dorsal/volar or combined SLIL repairs are very promising techniques for the early stages, taking into account the short term results of these procedures.

In my view, and if one takes into consideration the importance of wrist proprioception, based on the brilliant work of Elisabeth Hager (Karolinska Institute) and Richard Berger (Mayo Clinic), on the importance of the mechanoreceptors on carpus reflexes, one must believe that arthroscopic procedures may be have a great, beneficial contribution on the
Address for correspondence José Laranjeira Branco, MD, Rua Costa Pinto, 254, Monte Estoril, 2765-407, ESTORIL, Portugal (e-mail: Jsbranc055@gmail.com).

preservation of the integrity of these receptors and on the final, expected result.

To put it another way, open reconstructive techniques are of great value for more advanced lesions affecting all SLLC, knowing that the carpus disorganization has progressed in such way that a multiple ligament approach for carpus anatomy repositioning and function, is imperative. In this respect, and due to the magnitude of these reconstructive procedures, residual limitations are expected as far as range of wrist movement is concerned, although a good subjective result is generally obtained.

In closing, and knowing that in principle we are in the presence of a progressive lesion, I would like to emphasize the importance of an early diagnosis of an SL lesion.

The wrist societies should address the first line on the attendance of wrist injuries, namely traumatology centers, general orthopedic and plastic surgeons, that a minor wrist sprain or a wrist ganglion might be the initial sign of a SL lesion, and a referral to a wrist center, at the appropriate time, might make the all difference between an all inside arthroscopic procedure for an attenuation lesion and an open reconstructive, or even salvage procedure, for an irreversible SLAC wrist.

This is a combined work, which we must make together.
Copyright @ 2013 by Thieme Medical Publishers, Inc., 333 Seventh Avenue, New York, NY 10001, USA. Tel: +1(212) 584-4662.
DOI http://dx.doi.org/ $10.1055 / \mathrm{s}-0033-1353532$. ISSN 2163-3916. 